Subscriber access provided by CMU Libraries - http://library.cmich.edu

\title{
Article
}

\section{Preferred geometries and energies of sulfur- sulfur interactions in crystal structures}

Ivana S. Antonijevi\#, Goran V Janjic, Milos K. Milcic, and Snezana D. Zaric

Cryst. Growth Des., Just Accepted Manuscript • DOI: 10.1021/acs.cgd.5b01058 • Publication Date (Web): 07 Dec 2015

Downloaded from http://pubs.acs.org on December 11, 2015

\section{Just Accepted}

"Just Accepted" manuscripts have been peer-reviewed and accepted for publication. They are posted online prior to technical editing, formatting for publication and author proofing. The American Chemical Society provides "Just Accepted" as a free service to the research community to expedite the dissemination of scientific material as soon as possible after acceptance. "Just Accepted" manuscripts appear in full in PDF format accompanied by an HTML abstract. "Just Accepted" manuscripts have been fully peer reviewed, but should not be considered the official version of record. They are accessible to all readers and citable by the Digital Object Identifier (DOI®). "Just Accepted" is an optional service offered to authors. Therefore, the "Just Accepted" Web site may not include all articles that will be published in the journal. After a manuscript is technically edited and formatted, it will be removed from the "Just Accepted" Web site and published as an ASAP article. Note that technical editing may introduce minor changes to the manuscript text and/or graphics which could affect content, and all legal disclaimers and ethical guidelines that apply to the journal pertain. ACS cannot be held responsible for errors or consequences arising from the use of information contained in these "Just Accepted" manuscripts. 


\title{
Preferred geometries and energies of sulfur-sulfur
}

\section{interactions in crystal structures}

\author{
Ivana S. Antonijević, ${ }^{a}$ Goran. V. Janjić, ${ }^{a}$ Miloš K. Milčić, ${ }^{b}$ and Snežana D. Zarić*b,c \\ ${ }^{a}$ Institute of Chemistry, technology and metallurgy, University of Belgrade, Njegoševa 12, \\ Belgrade, Serbia \\ ${ }^{b}$ Department of Chemistry, University of Belgrade, Studentski trg 12-16, Belgrade, Serbia \\ ${ }^{c}$ Department of Chemistry, Texas A\&M University at Qatar, P. O. Box 23874, Doha, Qatar
}

\begin{abstract}
It has been demonstrated that sulfur-sulfur interactions can exist in various molecular systems. In this work we investigated sulfur-sulfur interactions in crystal structures of small molecules by analyzing geometric data from the Cambridge Structural Database (CSD) and by quantum chemical calculations. The analysis of cysteine residues $\left(\mathrm{R}_{-}-\mathrm{CH}_{2} \mathrm{SH}\right)$ in the crystal structures from the CSD indicates that in the sulfur-sulfur interactions the preferred is parallel orientation of two C-S-H planes. Quantum chemical calculations were performed on model systems of methanethiol dimers. The most stable geometry of methanethiol dimer with parallel orientation of C-S-H planes is significantly strong; the interaction energy is $-1.80 \mathrm{kcal} / \mathrm{mol}$ calculated at the very accurate $\operatorname{CCSD}(\mathrm{T}) / \mathrm{CBS}$ level. However, the strongest sulfur-sulfur
\end{abstract}


interaction in methanethiol dimer $(-2.20 \mathrm{kcal} / \mathrm{mol})$ is the geometry with $\sigma$-hole interaction, where the positive potential on one sulfur atom ( $\sigma$-hole) interacts with negative potential on the sulfur atom of the second molecule. SAPT decomposition of the interaction energies was performed in order to explain the nature of the interactions. This study point out importance of parallel interactions of cysteine residues and can be important for recognizing the sulfur-sulfur interactions in the crystal structures and biomolecules.

INTRODUCTION: It has been observed experimentally, and studied computationally, that some divalently-bonded atoms of Group VI interact in a noncovalent but highly directional manner with nucleophiles. ${ }^{1-8,10-15}$ In numerous crystal structures chalcogen atoms interact with other chalcogen species with intermolecular distances significantly shorter than the sum of their van der Waals radii. ${ }^{5,6}$ The early studies showed that $\mathrm{S}^{\cdots} \mathrm{S}$ interaction exist in crystal structures of sulfur compounds. Results of this work indicate that there are preferred directions of electrophilic and nucleophilic attack on one sulfur atom by another sulfur atom in crystals. ${ }^{16}$ Computational study of close $\mathrm{S} / \mathrm{Se}^{\cdots} \mathrm{O}$ contacts indicate that they are the result of an attractive electrostatic interaction. $^{17}$

The interactions of Group VI atoms are one type of $\sigma$-hole interactions; they are the consequence of the fact that chalcogen atoms can have regions of both positive ( $\sigma$-hole) and negative electrostatic potentials on their surfaces. The positive regions tend to be along the extensions of the bonds to these atoms, and the origin of this can be explained by $\sigma$-hole concept. $^{2-4,7-9}$ Theoretical studies of chalcogen-chalcogen $\sigma$-hole interactions ${ }^{10-15,18}$ showed that the strength of the interaction increases steadily from oxygen, via sulfur to selenium and reaches maximum for tellurium. With the increasing polarizability of the group VI elements when going from oxygen to tellurium, dispersion and inductive components become more important. ${ }^{1}$ 
The statistical analyses based on crystal structures have clearly demonstrated that $\mathrm{S}^{\cdots} \mathrm{X}(\mathrm{X}=\mathrm{O}$, $\mathrm{N}, \mathrm{S}$ ) interactions are widely present in proteins. ${ }^{19,20}$ The three-dimensional structure and the function of a protein are controlled by a number of weak nonbonding interactions, such as hydrogen bond, van der Waals forces, hydrophobic interaction, but also $\mathrm{S}^{\cdots} \mathrm{X}$ interactions. It had been previously considered that the sulfur-containing functional groups of cysteine and methionine are hydrophobic moieties in protein structures. However, studies showed that cysteine and methionine are able to form specific nonbonding interactions with nearby polar

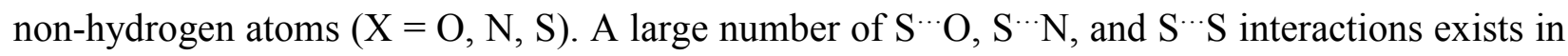
proteins. Most of close $\mathrm{S}^{\cdots} \mathrm{S}$ contacts in proteins can be assigned to $\mathrm{S}-\mathrm{S} \cdots \mathrm{S}-\mathrm{S}$ interaction. Analysis of $\mathrm{S}^{\cdots} \mathrm{X}$ interactions in four model proteins, phospholipase $\mathrm{A} 2$, ribonuclease $\mathrm{A}$, insulin, and lysozyme, indicate that $\mathrm{S}^{\cdots} \mathrm{X}$ interactions may be important factors that control not only the three-dimensional structure of proteins but also their functions. ${ }^{21} \mathrm{~S}^{\cdots} \mathrm{X}$ interactions are also of great importance for enzymatic reactions. $^{22,23}$

The $\mathrm{S}^{\cdots} \mathrm{S}$ interaction is also one of the major forces that influence the structures of organic conductors. $^{24,25}$ Namely, $\mathrm{S}^{\cdots} \mathrm{S}$ interactions are responsible for the molecular structures and functions of many well-known examples of organic conducting materials such as different derivates of tetrathiofulvalene (TTF). In these structures $\mathrm{S} \cdots \mathrm{S}$ interactions support the supramolecular assembly in the absence of any strong hydrogen bonding interactions. ${ }^{26,27}$ Investigation of the molecular packing in structures of a fused thiophene derivative reveals the important role of intermolecular $\mathrm{S}^{\cdots} \mathrm{S}$ interaction in directing the $2 \mathrm{D}$ self-assembly. ${ }^{28}$

Molecules containing divalent sulfur can also participate in $\mathrm{S}-\mathrm{H}^{\cdots} \mathrm{S}$ interactions. This type of interaction is studied on several systems including one with methanethiol which represent the side chain of the amino acid cysteine. Hydrogen-bonded methanethiol dimers have interaction energies of $\sim 3 \mathrm{kcal} / \mathrm{mol}^{29}$ 
It is very well known that aromatic molecules can form parallel (stacking) interactions. ${ }^{30-35}$ However, other molecules can be also involved in parallel non-covalent interactions. Parallel interactions between aromatic rings and water molecule were recognized by analyzing data in crystal structures from the Cambridge Structural Database (CSD). ${ }^{36,37}$ In parallel alignment interactions either the whole water molecule or one of its $\mathrm{O}-\mathrm{H}$ bonds lie parallel to the aromatic ring. We found that the strongest energies of the water-benzene interactions are calculated for the water position with the large horizontal displacements, out of the aromatic ring and out of the $\mathrm{C}-\mathrm{H}$ bond region, with one $\mathrm{O}-\mathrm{H}$ bond parallel to the plane of the benzene ring. The energy of this interaction is $-2.45 \mathrm{kcal} / \mathrm{mol}^{37}$ The parallel interactions between water and benzene are quite important since it was shown that in proteins from PDB and crystal structures from the CSD water molecules form significantly larger number of parallel interactions than well-known, relatively strong $\mathrm{OH}-\pi$ interactions. ${ }^{38}$

In this work, we present the detailed theoretical study of $\mathrm{S} \cdots \mathrm{S}$ interactions. The results are based on the analysis of data in the Cambridge Structural Database (CSD) and on quantum chemical calculations, including SAPT and very accurate $\operatorname{CCSD}(\mathrm{T}) / \mathrm{CBS}$ methods. To the best of our knowledge, this is the first study describing the preferred geometries of sulfur-sulfur interactions based on detailed statistical analysis of crystal structures data from the CSD combined with quantum chemical calculations. 


\section{METHODOLOGY}

In order to study the non-covalent $\mathrm{S}^{\cdots} \mathrm{S}$ interactions, we used theoretical approach based on two methods: statistical analysis of the data obtained from the crystal structures and quantum chemical calculations.

CSD search. The statistical study is based on the crystal structures archived in the Cambridge Structural Database (CSD, version 5.36). ${ }^{39-43}$ A CSD search was performed using the ConQuest 1.17 program $^{44}$ to extract all structures containing a cysteine residues and satisfying given geometric criteria. As a fragment for CSD search we used cysteine thiol residue which is bonded to any atom or group $\left(\mathrm{X}-\mathrm{CH}_{2} \mathrm{SH}\right)$. The geometrical parameters used to search $\mathrm{CSD}$ and to characterize the $\mathrm{S} \cdots \mathrm{S}$ interactions are displayed in Figure 1.

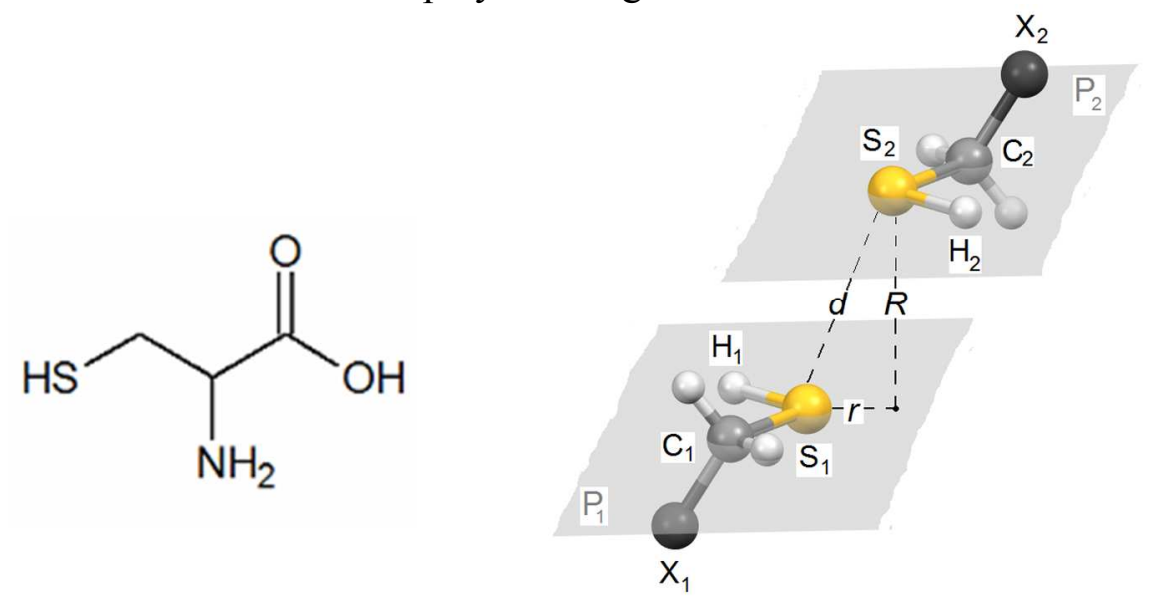

Figure 1. The cysteine structure and fragment used for the CSD search. Geometric parameters used for the description of $\mathrm{S}^{\cdots} \mathrm{S}$ interaction: planes $\mathrm{P}_{1}$ and $\mathrm{P}_{2}$ contain $\mathrm{C}_{1}, \mathrm{~S}_{1}, \mathrm{H}_{1}$ and $\mathrm{C}_{2}, \mathrm{~S}_{2}, \mathrm{H}_{2}$ atoms respectively; the distance between two sulfur atoms is $d$, and the distance between first sulfur atom $\left(\mathrm{S}_{1}\right)$ and $\mathrm{P}_{2}$ plane represents the normal distance $\mathrm{R}$. 
We considered that the $\mathrm{S}^{\cdots} \mathrm{S}$ interaction between two cysteine residues occurred if distance between two sulfur atoms, $d$, is smaller than $5.0 \AA$. For the statistical analysis, planes in the fragment were defined. The plane $\mathrm{P}_{1}$ is defined by the atoms $\mathrm{H}_{1}-\mathrm{S}_{1}-\mathrm{C}_{1}$, while plane $\mathrm{P}_{2}$ is defined by $\mathrm{H}_{2}-\mathrm{S}_{2}-\mathrm{C}_{2}$ atoms. Torsion angle define by atoms $\mathrm{H}_{1}-\mathrm{S}_{1} \cdots \mathrm{S}_{2}-\mathrm{H}_{2}$ was also used for the description of the interaction geometries.

Additionally, we investigate intermolecular $\mathrm{S}-\mathrm{H}^{\cdots} \mathrm{S}$ and $\mathrm{C}-\mathrm{H}^{\cdots} \mathrm{S}$ contacts between studied X$\mathrm{CH}_{2} \mathrm{SH}$ fragments. To find these interactions, we used geometric criteria; distance between hydrogen and sulfur atom $d\left(\mathrm{H}^{\cdots} \mathrm{S}\right)$ shorter than $3.3 \AA$ and S-H-S i.e. C-H-S angle greater than $90^{\circ} \cdot{ }^{45}$

\section{Quantum chemical calculations.}

For calculating energies of $\mathrm{S} \cdots \mathrm{S}$ interactions, two different quantum chemical methods were employed: supramolecular method (up to $\operatorname{CCSD(T)/CBS~level)~and~symmetry-adapted~}$ perturbation theory (SAPT) method. Results from SAPT calculations were also used to analyze the nature of $\mathrm{S} \cdots \mathrm{S}$ interactions.

Supramolecular calculations. All supramolecular calculations were performed using the Gaussian 09 program package. ${ }^{46}$ The geometry of an isolated methanethiol molecule was optimized (Figure S1 and Table S1, Supporting Information) and used for calculations of interaction energies in dimers. Geometry optimization was performed using the Møller-Plesset second-order perturbation method $(\mathrm{MP} 2)^{47}$ and the cc-pVQZ basis set. ${ }^{48}$ Calculations of interaction energies for model systems with parallel orientation were done using TPSS-D3 ${ }^{49,50}$ method and aug-cc-pVDZ ${ }^{51-53}$ basis set. For model system with normal orientation the interaction energy was calculated using the same functional but with Becke-Johnson ${ }^{54}$ damping (TPSS- 
D3BJ/aug-cc-pVDZ). Calculations of interaction energies for model system with maximized electrostatic interaction was done using MP2 method and cc-pVQZ basis set. These specified combinations of different methods and basis sets were used because they are in agreement with the results of $\operatorname{CCSD}(\mathrm{T})^{55}$ complete basis set limit for particular orientations. $\mathrm{CCSD}(\mathrm{T}) / \mathrm{CBS}$ interaction energies are calculated by applying the extrapolation scheme of Makie ${ }^{56}$ for different orientations of two methanethiol molecules (Table S2, Supporting Information). All calculated energies were corrected by the basis set superposition error (BSSE) using the Counterpoise method. $^{64}$

SAPT calculations. Perturbational SAPT method ${ }^{65}$ enables direct computation of interaction energy between monomers. Additionally, SAPT calculations can provide an interaction energy decomposition into four different, physically meaningful terms: electrostatic, exchange, induction and dispersion. Interaction energies for all studied model systems were calculated using SAPT method with density-fitting approximation (DF-SAPT2+3). ${ }^{66}$ It was shown previously that density fitting approximation can greatly reduce computational cost of SAPT calculations while introducing negligible errors. ${ }^{66,67}$ Standard aug-cc-PVTZ basis set was employed for all DF-SAPT2+3 calculations with aug-cc-PVTZ-JKFIT as auxiliary basis set for SCF density fitting computations and aug-cc-PVTZ-RI as auxiliary basis set for SAPT density fitting computations. Charge-transfer energy in SAPT analysis was obtained as the difference between induction term calculated in the dimer basis and in the monomer basis. ${ }^{68}$ DF-SAPT2+3 calculations were performed using PSI4 program. ${ }^{69}$

Electrostatic potential map. Electrostatic potential map of methanethiol molecule was obtained by calculating the wave function in the program Gaussian 09 using MP2 method and cc-pVQZ basis set. Map was visualized using the Wavefunction Analysis Program (WFA-SAS). $^{70}$ 


\section{RESULTS AND DISCUSSION}

Analyses of the data from crystal structures. To find intermolecular $\mathrm{S}$ ' $\mathrm{S}$ interactions between cysteine residues (X-CH${ }_{2} \mathrm{SH}$, Figure 1), a CSD search was performed. By searching the CSD 116 structures (Table S3, Supporting Information) and 290 S $\cdots$ S contacts with S-S distances $d$ smaller than $5.0 \AA$ were found. Statistical analysis of several geometrical parameters has been performed.

The distribution of $\mathrm{P}_{1} / \mathrm{P}_{2}$ angle formed by the C-S-H planes $\mathrm{P}_{1}$ and $\mathrm{P}_{2}$ (Figure 1) shows a tendency for values in the range from 0 to $10^{\circ}$, indicating parallel orientation of the $\mathrm{P}_{1}$ and $\mathrm{P}_{2}$ planes of interacting cysteine fragments (Figure 2). In a set of 290 contacts with $\mathrm{S} \cdots \mathrm{S}$ distance shorter than $5.0 \AA$, we found that parallel orientation $\left(\mathrm{P}_{1} / \mathrm{P}_{2}\right.$ angle less than $\left.10^{\circ}\right)$ exist in 200 contacts, which is about $69 \%$.

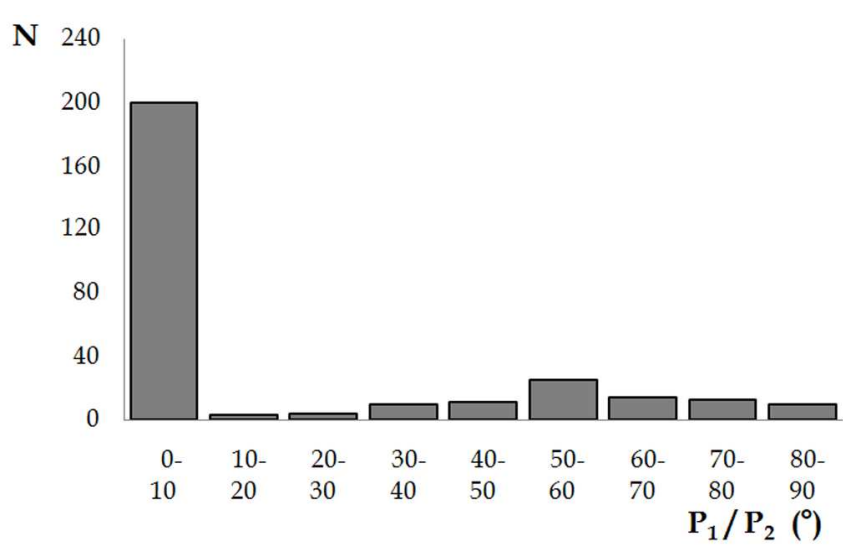

Figure 2. Distribution of $\mathrm{P}_{1} / \mathrm{P}_{2}$ angle in interactions with $\mathrm{S} \cdots \mathrm{S}$ distance below $5.0 \AA$.

Distribution of normal distance $(\mathrm{R})$ in data set with parallel orientation (200 contacts) shows that the most of parallel contacts have a values of normal distance in the range from 1.5 to $2.0 \AA$ (Figure 3). 


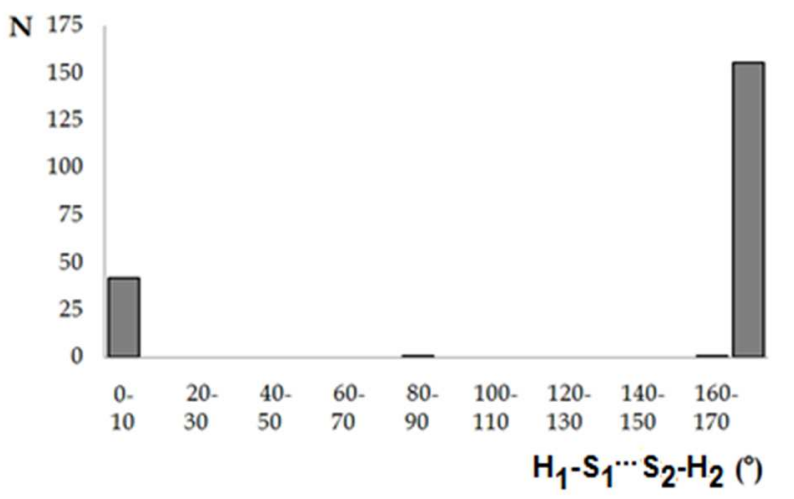

Figure 4. Distribution of $\mathrm{H}_{1}-\mathrm{S}_{1}{ }^{\cdots} \mathrm{S}_{2}-\mathrm{H}_{2}$ torsion angle in interactions with $\mathrm{S} \cdots \mathrm{S}$ distance below 5.0 $\AA$ and parallel orientations $\left(\mathrm{P}_{1} / \mathrm{P}_{2}\right.$ angle below $\left.10^{\circ}\right)$.

By examining S-H*'S interactions in set of 290 interactions, with $\mathrm{S}^{\cdots} \mathrm{S}$ distance below $5.0 \AA$, we found $43 \mathrm{~S}-\mathrm{H}^{\cdots} \mathrm{S}$ interactions $\left(d\left(\mathrm{H}^{\cdots} \mathrm{S}\right)<3.3 \AA\right.$ and S-H-S $\left.>90^{\circ}\right)$. In the data set with parallel orientation $\left(\mathrm{P}_{1} / \mathrm{P}_{2}\right.$ angle below $10^{\circ}, 200$ contacts $)$, there are 12 of these interactions. 
Distribution of $\mathrm{H}^{\cdots} \mathrm{S}$ distances (Figure 5a) shows that there is no pronounced tendency toward certain values of $d\left(\mathrm{H}^{\cdots} \mathrm{S}\right)$ distance. However, the most contacts have a distance value from 2.8 to 3.2 A. Distribution of S-H ${ }^{\cdots} \mathrm{S}$ angle (Figure $5 \mathrm{~b}$ ) shows a pronounced peak for values from 130 to $160^{\circ}$.

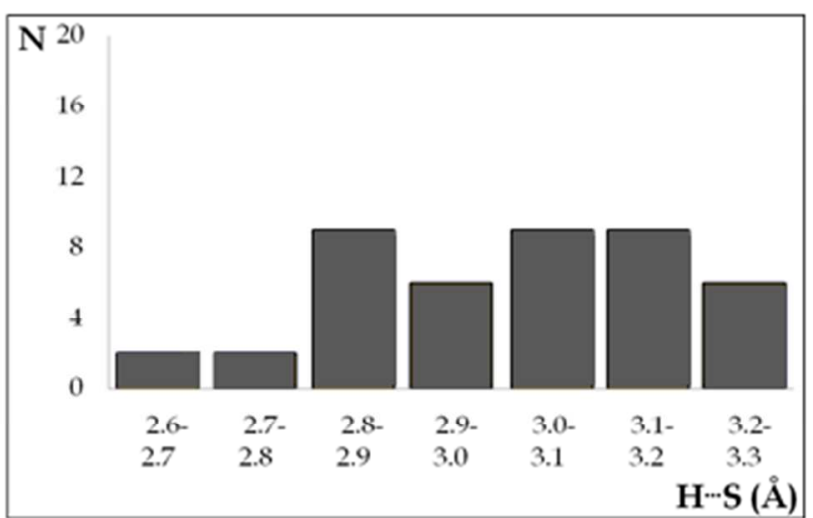

a)

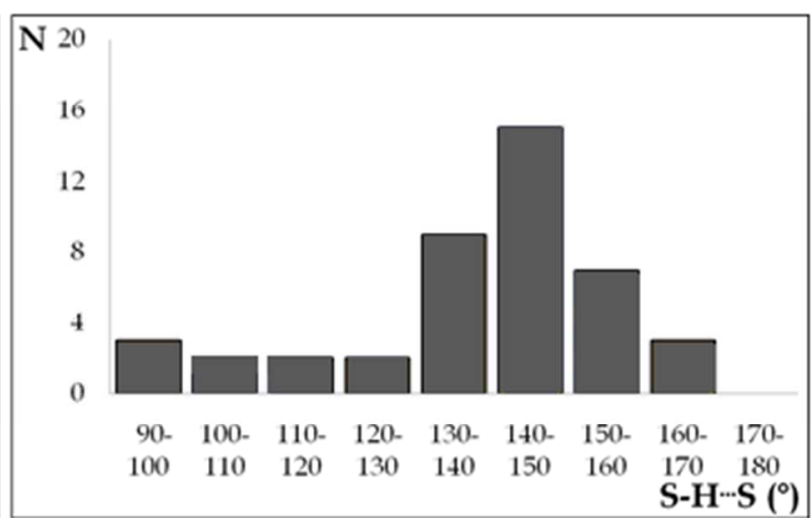

b)

Figure 5. The distribution of $\mathrm{H}^{\cdots} \mathrm{S}$ distance (a) and distribution of $\mathrm{S}-\mathrm{H}^{\cdots} \mathrm{S}$ angle (b) in $\mathrm{S}-\mathrm{H}^{\cdots} \mathrm{S}$ interactions.

In the data set with S-S distance below $5.0 \AA$, (290 contacts) we also searched for $\mathrm{C}-\mathrm{H}^{\cdots} \mathrm{S}$ interactions using criteria described in methodology $\left(d\left(\mathrm{H}^{\cdots} \mathrm{S}\right)<3.3 \AA\right.$ and $\left.\mathrm{C}-\mathrm{H}-\mathrm{S}>90^{\circ}\right)$. We found $109 \mathrm{C}-\mathrm{H}^{\cdots} \mathrm{S}$ interactions. In the data set with parallel orientation $\left(\mathrm{P}_{1} / \mathrm{P}_{2}\right.$ angle below $10^{\circ}$, 200 contacts), there are $82 \mathrm{C}-\mathrm{H}^{\cdots} \mathrm{S}$ interactions.

The distribution of $\mathrm{H}^{\cdots} \mathrm{S}$ distances show two peaks from 2.9 to $3.1 \AA$ and from 3.2 to $3.3 \AA$ (Figure 6a), while the distribution of $\mathrm{C}-\mathrm{H}^{\cdots} \mathrm{S}$ angle show peak between 100 and $120^{\circ}$ (Figure $6 \mathrm{~b}$ ).

By searching for $\mathrm{C}-\mathrm{H}^{\cdots} \mathrm{S}$ interactions $\left(d\left(\mathrm{H}^{\cdots} \mathrm{S}\right)<3.3 \AA\right.$ and $\left.\mathrm{C}-\mathrm{H}-\mathrm{S}>90^{\circ}\right)$ between cysteine residues in the CSD, without restriction of $\mathrm{S}^{\cdots} \mathrm{S}$ distance less than $5.0 \AA$, the number of obtained structures was 104 with $210 \mathrm{C}-\mathrm{H}^{\cdots} \mathrm{S}$ interactions. The distribution of $\mathrm{H}^{\cdots} \mathrm{S}$ distance and $\mathrm{C}-\mathrm{H}^{\cdots} \mathrm{S}$ angle (Figure 7) are similar to the distributions in Figure 6, with somewhat less pronounced 
peaks for $\mathrm{H}^{\cdots} \mathrm{S}$ distance, and more pronounced peak for $\mathrm{C}-\mathrm{H}^{\cdots} \mathrm{S}$ angle (in the range from 110 to $120^{\circ}$, Figure 7).

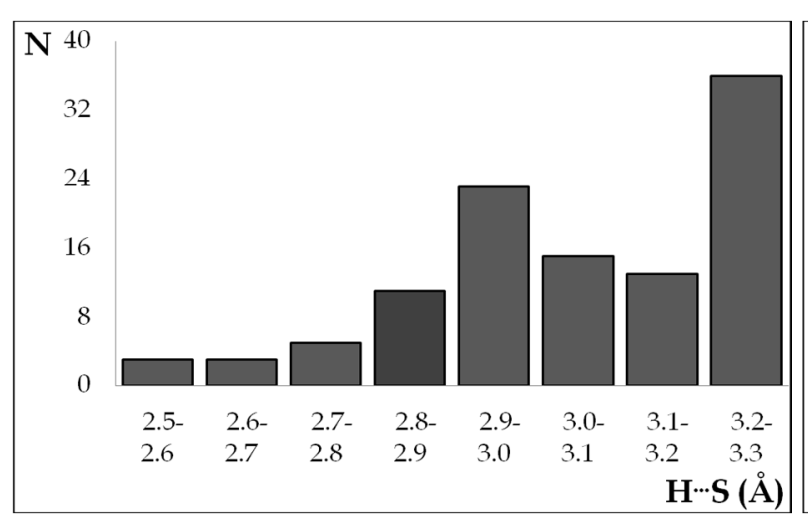

a)

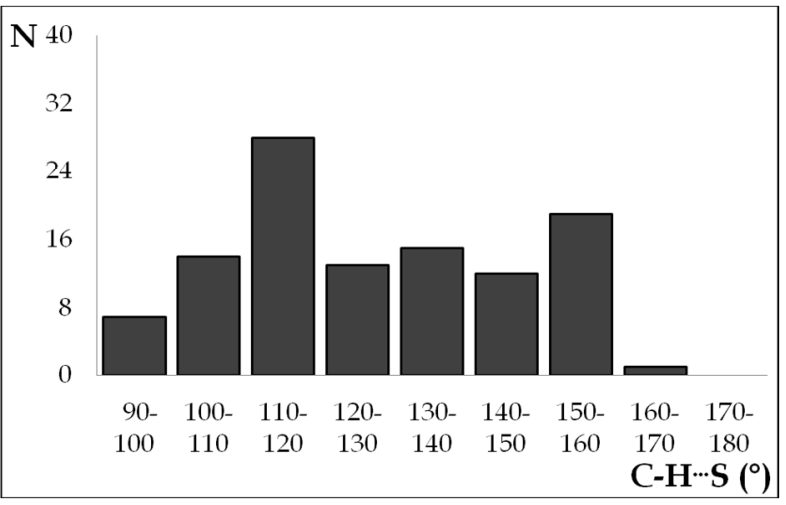

b)

Figure 6. Graphs of the: a) distribution of $\mathrm{H}^{\cdots} \mathrm{S}$ distance b) distribution of $\mathrm{C}-\mathrm{H}^{\cdots} \mathrm{S}$ angle in $\mathrm{C}$ $\mathrm{H}^{\cdots} \mathrm{S}$ interactions with $\mathrm{S} \cdots \mathrm{S}$ distance below $5.0 \AA$.

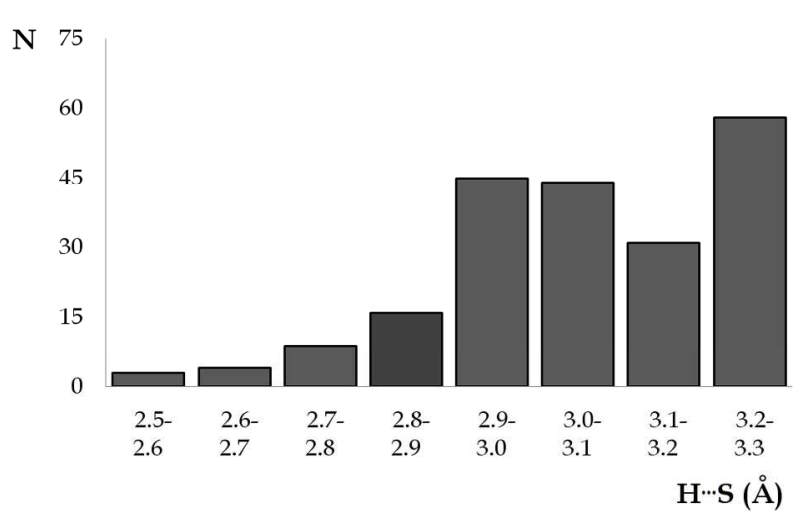

a)

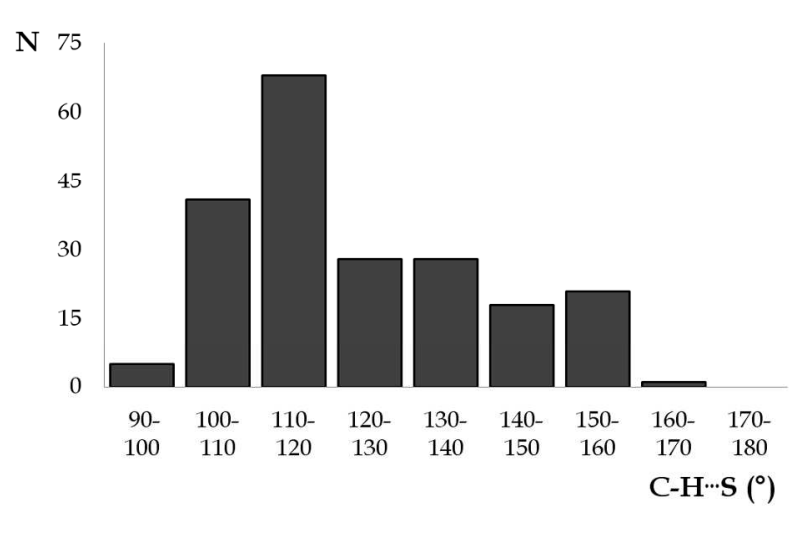

b)

Figure 7. Graphs of the: a) distribution of $\mathrm{H}^{\cdots} \mathrm{S}$ distance b) distribution of $\mathrm{C}-\mathrm{H}^{\cdots} \mathrm{S}$ angle in the C$\mathrm{H}^{\cdots} \mathrm{S}$ interactions. 


\section{Quantum chemical calculations}

Electrostatic potential map. As was mentioned in the introduction, sulfur atom can have region of negative, as well as region of positive potential, enabling electrostatic attraction between two sulfur atoms. ${ }^{2,4,7,8}$ In order to determine distribution of charges in cysteine residue the electrostatic potential map was calculated on model system of methanethiol molecule. Electrostatic potential map shows negative region on the surface of the sulfur atom (Figure 8, blue color). However, in the direction of S-H bond, small area of positive potential on sulfur atom can be observed, more precisely the positive potential is above $\mathrm{C}-\mathrm{S}$ bond (Figure 8, yellow color). The most positive potentials are on the hydrogen atoms (Figure 8, red color).
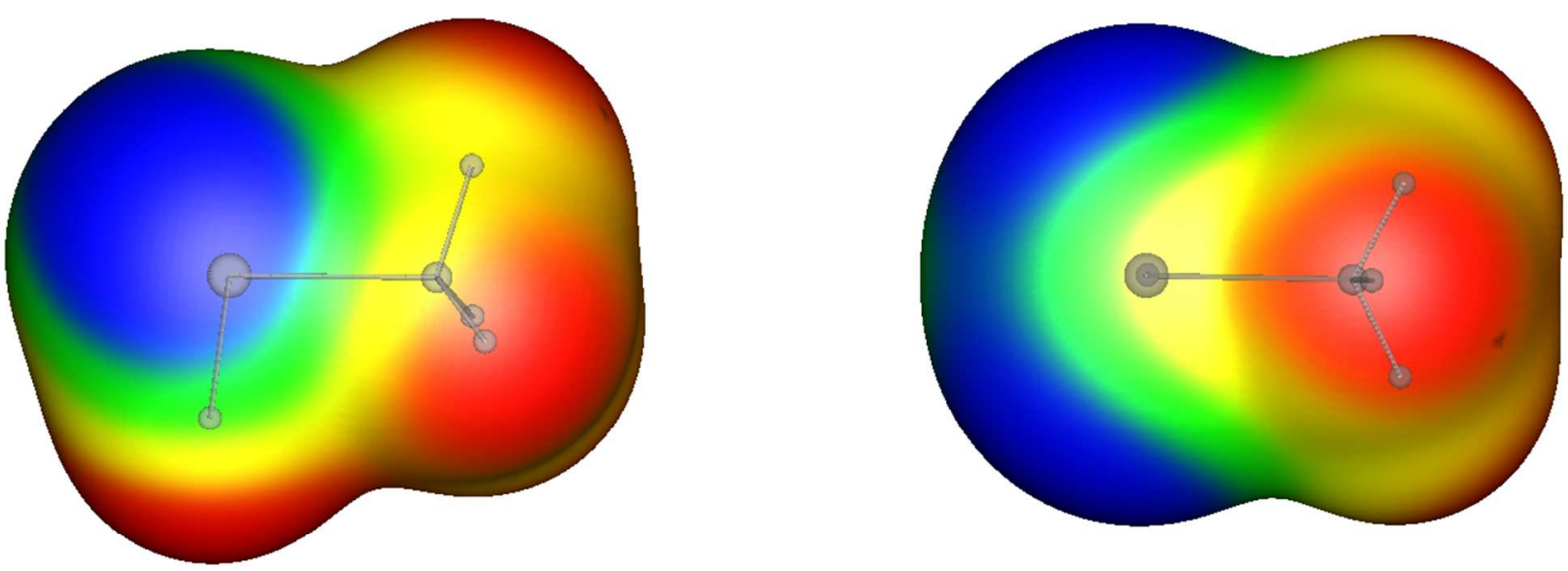

Figure 8. Two views of electrostatic potential map of the methantiole molecule; Red: more positive than $10.35 \mathrm{kcal} / \mathrm{mol}$, yellow: 0.00 to $10.35 \mathrm{kcal} / \mathrm{mol}$, green: -0.125 to $-10.54 \mathrm{kcal} / \mathrm{mol}$, blue: more negative than $-10.54 \mathrm{kcal} / \mathrm{mol}$.

The electrostatic potential map enabled to understand interactions in model systems. We also made one model systems, where negative potential on sulfur atom of one molecule is in contact with the positive potential on sulfur atom of the second molecule. 
Energies of interactions. In order to determine whether interactions between cysteine residues in parallel orientations are attractive and not just the consequence of packing in the crystal structures, energies of interactions between two methanethiol molecules were calculated using quantum chemical calculations.

Quantum chemical calculations were performed on five model systems (Figure 9). Model systems were based on the results obtained by analyzing data from the crystal structures, and on distribution of electron density in methanethiol molecule. Since in the crystal structures interactions with parallel orientation were observed (Figure 2), we made model systems A, B, and C. In model systems A, B, and C molecules are parallel (C-S-H planes of two molecules are parallel) and have $\mathrm{H}_{1}-\mathrm{S}_{1}{ }^{\cdots} \mathrm{S}_{2}-\mathrm{H}_{2}$ torsion angle value of $180^{\circ}$; the value that was observed in crystal structures (Figure 4). In model system A the sulfur atoms are one above the other, in model system B the sulfur atom of one molecule is above the middle of S-H bond of the other, while in model system $\mathrm{C}$, the sulfur atom of one methanethiol molecule is located above the middle of the C-S bond of the other molecule (Figure 9).

In model system D orientation of two methanethiol molecules is normal; the C-S-H planes of two molecules are perpendicular. Model system E is based on the distribution of charge in methanethiol molecule. As was mentioned, the electrostatic potential map (Figure 8) shows positive and negative regions on sulfur atom. In the model system E orientation of the two molecules is such that the positive part of the sulfur atom of one methanethiol molecule is directed toward the negative part of the sulfur of other molecule. However, in this structure hydrogen of C-H bond is also involved in the interaction with the sulfur atom. 


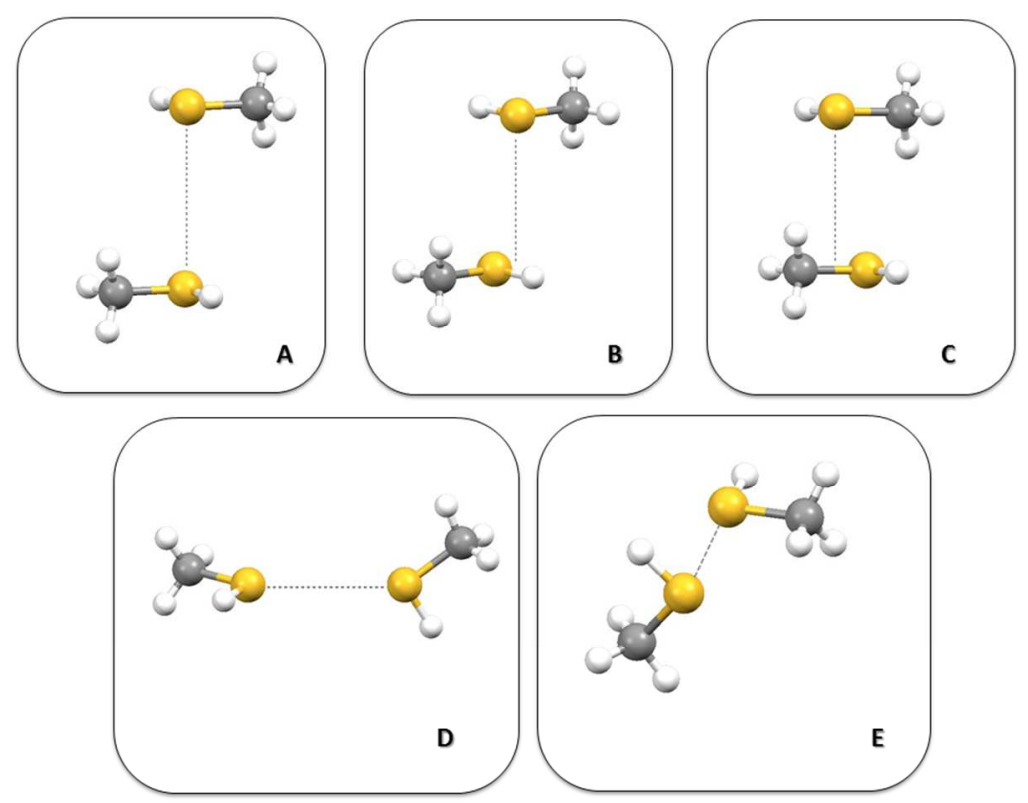

Figure 9. Model systems of methanethiol dimers used for quantum chemical calculations of interaction energies. (The coordinates are given in Tables S4-S8, Supporting Information).

For the geometries of the parallel orientation (model systems A to C) the monomer geometries were kept rigid, while the normal distance $\mathrm{R}$ was systematically varied to find the $\mathrm{R}$ with the strongest interaction (Figure S2, Supporting Information). In the model systems D and E the distance $d$ between two sulfur atoms was systematically changed.

The interactions energies calculated with $\operatorname{CCSD}(\mathrm{T}) / \mathrm{CBS}$ and SAPT methods were calculated for each model system and presented in Table 1. The SAPT interactions energies are in very god agreement with $\mathrm{CCSD}(\mathrm{T}) / \mathrm{CBS}$ energies.

The results of quantum chemical calculations show that the $\mathrm{S} \cdots \mathrm{S}$ interaction is strongest in the case of model system $\mathrm{E}$ that has orientation with maximized electrostatic interaction between two sulfur atoms. The CCSD(T)/CBS interactions energy is $-2.20 \mathrm{kcal} / \mathrm{mol}$. This interaction also has the shortest distance between sulfur atoms (d) of $3.6 \AA$, which is slightly less than the sum of their van der Waals radii ${ }^{71}$ which is $3.66 \AA$. Although, in this structure electrostatic interaction 
between two sulfur atoms is maximized, there is also a $\mathrm{C}-\mathrm{H}^{\cdots} \mathrm{S}$ interaction with $\mathrm{H}^{\cdots} \mathrm{S}$ distance of $3.05 \AA$ and $\mathrm{C}-\mathrm{H}^{\cdots} \mathrm{S}$ angle of $129.9^{\circ}$.

All model systems with parallel orientations (A, B, and C) have significantly weaker interactions than model system E. Among parallel orientations the most stable is model system C, with sulfur above S-C bond; the interactions energy is $-1.80 \mathrm{kcal} / \mathrm{mol}$, and distance $d$ is $4.0 \AA$. The relatively strong interaction energy for this model system can be explained by the electrostatic potential map. Methanethiol molecules are in such orientation that the negative region on the sulfur atom (Figure 8, blue color,) is located above the positive region along the C-S bond (Figure 8, yellow color) which contributes to the interaction energy in this model system. However, in this orientation, there is an additional stabilization by two $\mathrm{C}-\mathrm{H}^{\cdots} \mathrm{S}$ interactions. These interactions are formed between the sulfur atom in one molecule and a hydrogen atom from the methyl group of the second molecule (Figure 9) with $\mathrm{H}^{\cdots} \mathrm{S}$ distance of $3.3 \AA$ and $\mathrm{C}-\mathrm{H}^{\cdots} \mathrm{S}$ angle of $122.6^{\circ}$. The model system $\mathrm{C}$ is very similar to model system used in previous the DFT-D study of $\mathrm{C}-\mathrm{H}^{\cdots} \mathrm{S}$ interactions in methanethiol dimer ${ }^{72}$ were at BLYP-D*, BLYP-D, and B3LYP-D level, the calculated binding energies were $-2.28 \mathrm{kcal} / \mathrm{mol},-2.68$ $\mathrm{kcal} / \mathrm{mol}$ and $-2.81 \mathrm{kcal} / \mathrm{mol}$, respectively.

The interaction energy for model system B (sulfur atom above $\mathrm{S}-\mathrm{H}$ bond) is significantly weaker $-0.72 \mathrm{kcal} / \mathrm{mol}$, while the interaction energy for model system $\mathrm{A}$, with the sulfur atoms one above the other, is the weakest $-0.52 \mathrm{kcal} / \mathrm{mol}$.

For model system $\mathrm{C}$, change of torsion angle $\mathrm{H}_{1}-\mathrm{S}_{1}{ }^{\cdots} \mathrm{S}_{2}-\mathrm{H}_{2}$ values was studied. The data from the crystal structures show that $\mathrm{H}_{1}-\mathrm{S}_{1} \cdots \mathrm{S}_{2}-\mathrm{H}_{2}$ torsion angle in most of the contacts has value of $180^{\circ}$ (Figure 4). The $\mathrm{H}_{1}-\mathrm{S}_{1} \cdots \mathrm{S}_{2}-\mathrm{H}_{2}$ torsion angle in the initial geometry of model system $\mathrm{C}$ has a value of $180^{\circ}$. To investigate whether the change of torsion angle influence strength of the interaction energy we decrease the value of $\mathrm{H}_{1}-\mathrm{S}_{1} \cdots \mathrm{S}_{2}-\mathrm{H}_{2}$ torsion angle from the initial $180^{\circ}$ to 
$90^{\circ}$. For geometry with torsion angle of $90^{\circ}$, the interaction energy on TPSS-D3/aug-cc-pVDZ level is $-1.36 \mathrm{kcal} / \mathrm{mol}$, indicating that decreasing $\mathrm{H}_{1}-\mathrm{S}_{1} \cdots \mathrm{S}_{2}-\mathrm{H}_{2}$ torsion angle decreases interaction energy. Hence, the strength of interaction depends on the values of torsion angle.

The energy for normal (model system D) orientation is rather weak and has a value of -0.37 $\mathrm{kcal} / \mathrm{mol}$ (Table 1) with the long distance $d$ of $4.0 \AA$.

Table 1. The interaction energy values and the distance between the sulfur atoms for the model systems (Figure 9)

\begin{tabular}{lccc}
\hline \multicolumn{1}{c}{ Model system } & $\begin{array}{c}\Delta \mathbf{E} \\
\mathbf{C C S D}(\mathbf{T}) / \mathbf{C B S} \\
(\mathbf{k c a l} / \mathbf{m o l})\end{array}$ & $\begin{array}{c}\Delta \mathbf{E} \\
\mathbf{S A P T 2 + 3} \\
(\mathbf{k c a l} / \mathbf{m o l})\end{array}$ & $\mathbf{d}(\mathbf{\AA})$ \\
\hline Parallel orientation & & & \\
A & -0.52 & -0.51 & 4.50 \\
B & -0.72 & -0.73 & 4.15 \\
C & -1.80 & -1.82 & 4.00 \\
Normal orientation & & & 4.00 \\
D & -0.37 & -0.34 & \\
Electrostatic model & & & 3.60 \\
E & & & \\
\hline
\end{tabular}

The results of quantum chemical calculations show some agreement with results of the CSD search. The data from the CSD show that parallel orientations are preferred in crystal structures (Figure 2), that is in agreement with calculated interaction energies for parallel and normal orientations; parallel orientation is more stable than normal orientation (Table 1). Also, the distribution of the values of torsion angle shows that the preferred orientations are with torsion angle in the range $170^{\circ}-180^{\circ}$ (Figure 4), while the results of quantum chemical calculations on 
model system $\mathrm{C}$ show that the geometry with torsion angle of $180^{\circ}$ is more stable that geometry with torsion angle $90^{\circ}$.

However, results of CSD search showed tendency toward parallel orientation of cysteine fragments, while the calculated most stable geometry is model system E, where molecules are not in parallel orientation (Table 1).

A larger number of structures with parallel orientation observed in crystal structures can be explained by the influence of supramolecular structure. It seems that the parallel interactions enable better packing in crystals that could stabilize structures for more than $0.4 \mathrm{kcal} / \mathrm{mol}$, what is the energy difference between the most stable model system $\mathrm{E}(-2.20 \mathrm{kcal} / \mathrm{mol})$ and parallel model system C (-1.80 kcal/mol).

It should be noted that most of the interactions we have studied in this paper are not of $\sigma$-hole type. The major point of our research is that the interactions between two cysteine residues have very frequently parallel C-S-H planes in crystal structures, while calculated interactions energy is significantly strong.

Interaction energy decomposition. Results of the interaction energy decomposition obtained by DF-SAPT2+3 method are presented in Table 2 . For model systems B, C and E electrostatic energy term is negative (i.e. attractive) and for model systems A and D slightly positive (i.e. repulsive). As expected, highest contribution of electrostatic energy term to total binding energy is in model system E and only for this model system electrostatic energy term is more negative than the total interaction energy indicating a net repulsive contribution from other energy terms (exchange, induction and dispersion). 
Table 2. Results of the SAPT interaction energy decomposition for model systems (Figure 9)

\begin{tabular}{|c|c|c|c|c|c|c|}
\hline Model system & $\begin{array}{l}\mathrm{E}_{\text {electrostatic }} \\
\text { (kcal/mol) }\end{array}$ & $\begin{array}{l}\mathbf{E}_{\text {exchange }} \\
\text { (kcal/mol) }\end{array}$ & $\begin{array}{l}\mathrm{E}_{\text {induction }} \\
\text { (kcal/mol) }\end{array}$ & $\begin{array}{l}\mathbf{E}_{\text {dispersion }} \\
(\mathrm{kcal} / \mathrm{mol})\end{array}$ & $\begin{array}{l}\mathbf{E}_{\text {charge-transfer }} \\
(\mathrm{kcal} / \mathrm{mol})\end{array}$ & $\begin{array}{l}\mathbf{E}_{\text {"net-dispersion" }}{ }^{\mathrm{a}} \\
(\mathrm{kcal} / \mathrm{mol})\end{array}$ \\
\hline $\mathbf{A}$ & 0.049 & 0.533 & -0.118 & -0.977 & -0.027 & -0.444 \\
\hline B & -0.327 & 1.420 & -0.217 & -1.605 & -0.074 & -0.185 \\
\hline $\mathbf{C}$ & -1.642 & 3.059 & -0.443 & -2.797 & -0.122 & 0.262 \\
\hline D & 0.081 & 0.770 & -0.122 & -1.067 & -0.038 & -0.297 \\
\hline $\mathbf{E}$ & -2.935 & 5.059 & -0.794 & -3.556 & -0.480 & 1.503 \\
\hline
\end{tabular}

a "net dispersion" is calculated as the sum of exchange and dispersion terms.

The exchange energy term, which arises due to electron exchange between the monomers when the molecules are close, have large positive values for all the model systems. Since most of the contribution in exchange energy term comes from orbital overlap between molecules this term will depend strongly on intermolecular distances and orientation of the molecules. This trend can be observed for model systems with parallel orientation (Table 2). Model system $\mathrm{C}$ with shortest intermolecular distances has the highest repulsive value for exchange energy term. Small value for exchange term in model system $\mathrm{D}$ can be explained with sulfur-sulfur distances longer than the sum of their van der Waals radii and normal orientation of the molecules, so very little orbital overlap between molecules will occur in this model system. Highest value for exchange energy term is calculated for model system E, where two sulfur atoms are at the distances shorter than the sum of their van der Waals radii, thus strong orbital overlap between those two atoms exists.

In all investigated model systems the largest attractive contribution to the total binding energy comes from dispersion energy term (Table 2). For the model systems B and C dispersion energy 
term is by $1.15-1.28 \mathrm{kcal} / \mathrm{mol}$ more negative than electrostatics, but for the model system $\mathrm{E}$ this difference is only $0.62 \mathrm{kcal} / \mathrm{mol}$.

The induction contribution to the binding energy is much smaller than dispersion energy component and is most favorable for model system E (Table 2). In SAPT analysis charge-transfer energy is hidden as the part of the induction energy term, and can be evaluated as the difference between induction energy terms calculated in the dimer basis and monomer basis. For model systems A, B, C and D charge-transfer energy is rather small contributing from 5.1 to $11.3 \%$ tot total binding energy. On the other hand, charge-transfer energy for model system E is large, contributing $21.5 \%$ to total binding energy and more than $60 \%$ to induction energy term.

Since dispersion and exchange energy terms are usually similar in magnitude and opposite in sign, interesting results of SAPT analysis can be obtained by introducing a new term called "net dispersion" 73 as the sum of exchange and dispersion energy terms (Table 2). Data in Table 2 show that values of the "net dispersion" term are negative for model systems A, B and D, slightly positive for model system $\mathrm{C}$ and large positive for model system $\mathrm{E}$.

Results of the SAPT energy decomposition clearly indicates that dispersion is the main attractive force in all model systems. Binding in model system E also has very strong electrostatic interactions between molecules and large contribution from charge-transfer energy.

\section{CONCLUSIONS}

The results of analyzing data on sulfur-sulfur interactions between cysteine fragments (R$\mathrm{CH}_{2} \mathrm{SH}$ ) in the crystal structures from the Cambridge Structural Database showed that geometries with parallel C-S-H groups are preferred. The calculated CCSD(T)/CBS interaction energies show that the most stable geometry with parallel orientation has significant interaction energy of $-1.80 \mathrm{kcal} / \mathrm{mol}$. The model system with maximized electrostatic $\sigma$-hole interaction has the 
strongest interaction energy, $-2.20 \mathrm{kcal} / \mathrm{mol}$. Although the energy of parallel orientation is less strong, the difference in energy is only $0.40 \mathrm{kcal} / \mathrm{mol}$, indicating possibility for parallel orientation stabilization in supramolecular structures.

Results of the SAPT energy decomposition indicate that dispersion is the main attractive force in all model systems. As one can anticipate, SAPT data confirmed that binding in model system with $\sigma$-hole interaction has strong electrostatic interaction contribution.

This study show preferred geometries of sulfur-sulfur interactions between cysteine fragments ( $\mathrm{R}-\mathrm{CH}_{2} \mathrm{SH}$ ) that can be important for recognizing the sulfur-sulfur interactions in various molecular systems.

\title{
ASSOCIATED CONTENT
}

Supporting Information. Refcode list of crystal structures from CSD which are used for statistical analysis. Vibrational frequencies for optimized geometry of methanethiol molecule (Figure S1and Table S1) and Cartesian coordinates for the model systems (Tables S4-S8). The potential energy curves of studied model systems for different methanethiol dimers (Figure S3S7). Results of QTAIM and NCI index method analysis. This information is available free of charge via the Internet at http://pubs.acs.org/.

\author{
AUTHOR INFORMATION \\ Corresponding Author \\ Prof. Snežana D. Zarić \\ *Department of Chemistry, University of Belgrade, Studentski trg 16, 11000 Belgrade, Serbia. \\ Department of Chemistry, Texas A\&M University at Qatar, P.O. Box 23874, Doha, Qatar.
}


E-mail: szaric@chem.bg.ac.rs

Author Contributions: I.S.A. performed quantum chemical calculations, interpreted the data, and prepared the manuscript.; G.V.J. proposed topic and performed CSD search.; M.K.M. has done SAPT, QTAIM and NCI index method calculations and analyzed data.; S.D.Z. analyzed the results, supervised, wrote and edited the manuscript.

Funding Sources: This work was supported by the Serbian Ministry of Education, Science and Technological Development (grant 172065).

\section{Notes}

The authors declare no competing financial interest.

\section{ACKNOWLEDGMENT}

We thank Dr. Jane S. Murray from the University of New Orleans and Dr. Horst Borrmann from Max-Plank Institute in Dresden for support.

\section{REFERENCES}

(1) Bleiholder, C.; Werz, D. B.; Köppel, H.; Gleiter, R. J. Am. Chem. Soc. 2006, 128, 26662674.

(2) Politzer, P.; Murray, J. S; Concha, M. C. J. Mol. Model. 2008, 14, 659-665.

(3) Basu, P.; Stolz, J. F.; Smith, M. T. Curr. Sci. 2003, 84, 1412-1418.

(4) Murray, J. S.; Lane, P.; Clark, T.; Politzer P. J. Mol. Model. 2007, 13, 1033-1038.

(5) Gleiter, R.; Werz, D. B.; Rausch, B. J. Chem. - Eur. J. 2003, 9, 2676-2683. 
(6) Reinheimer, E. W.; Fourmigué, M.; Dunbar, K. R. J. Chem. Crystallogr. 2009, 39, 723729.

(7) Politzer, P.; Murray, J. S.; Clark, T. Phys. Chem. Chem. Phys. 2013, 15, 11178-11189.

(8) Murray, J. S.; Lane, P.; Politzer, P. J. Mol. Model. 2009, 15, 723-729.

(9) Politzer, P.; Murray, J. S.; Janjić, G. V.; Zarić,S. D. Crystals 2014, 4(1), 12-31.

(10) Silaghi-Dumitrescu, R.; Lupan, A. Cent. Eur. J. Chem. 2013, 11(3), 457-463.

(11) Bleiholder, C.; Gleiter, R.; Werz, D. B.; Köppel, H. Inorg. Chem. 2007, 46, 2249-2260.

(12) Sanz, P.; Yáñez, M.; Mó, O. Chem. - Eur. J. 2002, 8, 3999-4007.

(13) Iwaoka, M.; Takemoto, S.; Tomoda, S. J. Am. Chem. Soc. 2002, 124, 10613-10620.

(14) Sanz, P.; Yáñez, M.; Mó, O. J. Phys. Chem. A. 2002, 106, 4661-4668.

(15) Junming, L.; Yunxiang, L.; Subin, Y.; Weiliang, Z. Struct. Chem. 2011, 22, 757-763.

(16) a) RosenfieldJr, R. E.; Parthasarathy, R.; Dunitz J. D. J. Am. Chem. Soc. 1977, 99 (14), 4860-4862. b) Guru Row, T. N.; Parthasarathy, R. J. Am. Chem. Soc. 1981,103, 477.

(17) Burling, T. F.; Goldstein, B. M. J. Am. Chem. Soc. 1992, 114 (7), 2313-2320.

(18) Sanz, P.; Mó, O.; Yáñez, M. Phys. Chem. Chem. Phys. 2003, 5, 2942-2947.

(19) Iwaoka, M.; Takemoto, S.; Okada, M.; Tomoda, S. Chem. Lett. 2001, 132-133.

(20) Iwaoka, M.; Takemoto, S.; Okada, M.; Tomoda, S. Bull. Chem. Soc. Jpn. 2002, 75, 16111625. 
(21) Iwaoka, M.; Isozumi, N. Molecules 2012, 17, 7266-7283.

(22) Nagao, Y.; Honjo, T.; Iimori, H.; Goto, S.; Sano, S.; Shiro, M.; Yamaguchi, K.; Sei, Y. Tetrahedron Lett. 2004, 45, 8757-8761.

(23) Nakamura, T.; Yamamoto, T.; Abe, M.; Matsumura, H.; Hagihara, Y.; Goto, T.; Yamaguchi, T.; Inoue, T. Proc. Nat. Acad. Sci. USA. 2008, 105, 6238-6242.

(24) Bai, M.; Thomas, S. P.; Kottokkaran, R.; Nayak, S. K.; Ramamurthy, P. C.; Row, G.T.N. Cryst. Growth Des. 2014, 14, 459-466.

(25) Cole, J. M.; Aherne, C. M.; Waddell, P. G.; Banister, A. J.; Batsanov, A. S.; Howard, J. A. K. Polyhedron 2012, 45, 61-70.

(26) Hudhomme, P.; Le Moustarder, S.; Durand, C.; Gallego-Planas, N.; Mercier, N.; Blanchard, P.; Levillain, E.; Allain, M.; Gorgues, A.; Riou, A. Chem. - Eur. J. 2001, 7(23), 50705083.

(27) Mas-Torrent, M.; Hadley, P.; Bromley, S. T.; Ribas, X.; Tarrés, J.; Mas, M.; Molins, E.; Veciana, J.; Rovira, C. J. Am. Chem. Soc. 2004, 126, 8546-8553.

(28) Wang, X.; Jiang, W.; Chen, T.; Yan, H.; Wang, Z.; Wana, L.; Wang, D. Chem. Commun. 2013, 49, 1829-1831.

(29) Mintz, B. J.; Parks J. M. J. Phys. Chem. A 2012, 116, 1086-1092.

(30) Salonen, L. M.; Ellermann, M.; Diederich, F. Angew. Chem., Int. Ed. 2011, 50, 4808.

(31) Lee, E. C.; Kim, D.; Jurečka, P.; Tarakeshwar, P.; Hobza, P.; Kim, K. S. J. Phys. Chem. A, 2007, 111, 3446. 
(32) Ninković, D. B.; Janjić, G. V.; Veljković, D. Ž.; Sredojević, D. N.; Zarić, S. D. ChemPhysChem, 2011, 12, 3511.

(33) Ninković, D. B.; Andrić J. M.; Zarić, S. D. ChemPhysChem 2013, 14, 237.

(34) Sinnokrot, M. O.; Valeev, E. F.; Sherrill, C. D. J. Am. Chem. Soc. 2002, 124, 10887.

(35) Raju, R. K.; Bloom, J. W. G.; An, Y.; Wheeler, S. E. ChemPhysChem 2011, 12, 3116.

(36) Ostojić, B. D.; Janjić, G.V.; Zarić, S.D. Chem. Commun. 2008, 6546.

(37) Janjić, G. V.; Veljković, D. Ž.; Zarić, S. D. Cryst. Growth Des. 2011, 11(7), 2680.

(38) Janjić, G. V.; Malkov, S. N.; Živković, M. V.; Zarić, S. D. Phys. Chem. Chem. Phys. 2014, $16,23549$.

(39) Allen, F. H. Acta Cryst. 2002, B58, 380-388.

(40) J. van de Streek, Acta Cryst. 2006, B62, 567-579.

(41) Orpen, A. G. Acta Cryst. 2002, B58, 398-406.

(42) Allen, F. H.; Motherwell, W. D. S. Acta Cryst. 2002, B58, 407-422.

(43) Taylor, R. Acta Cryst. 2002, D58, 879-888.

(44) Bruno, J. I.; Cole, C. J.; Edgington, R. P.; Kessler, M.; Macrae, F. C.; McCabe, P.; Pearson, J.; Taylor, R. Acta Cryst. 2002, B58, 389-397.

(45) a) Taylor, R.; Kennard O. J. Am. Chem. Soc. 1982, 104, 5063-5070. b) Zhou P.; Tian F.; Lv F.; Shang Z. Proteins 2009, 76, 151-163. 
(46) Frisch, M. J.; Trucks, G. W.; Schlegel, H. B.; Scuseria, G. E.; Robb, M. A.; Cheeseman, J. R.; Scalmani, G.; Barone, V.; Mennucci, B.; Petersson, G. A.; Nakatsuji, H.; Caricato, M.; Li, X.; Hratchian, H. P.; Izmaylov, A. F.; Bloino, J.; Zheng, G.; Sonnenberg, J. L.; Hada, M.; Ehara, M.; Toyota, K.; Fukuda, R.; Hasegawa, J.; Ishida, M.; Nakajima, T.; Honda, Y.; Kitao, O.; Nakai, H.; Vreven,T.; Montgomery Jr., J. A.; Peralta, J. E.; Ogliaro, F.; Bearpark, M.; Heyd, J. J.; Brothers, E; Kudin, K. N.; Staroverov, V. N.; Kobayashi, R.; Normand, J.; Raghavachari, K.; Rendell,; Burant, A. J. C.; Iyengar, S. S.; Tomasi, J.; Cossi, M.; Rega, N.; Millam, J. M.; Klene, M.; Knox, J. E.; Cross, J. B.; Bakken, V.; Adamo, C.; Jaramillo, J.; Gomperts, R.; Stratmann, R. E.; Yazyev, O.; Austin, A. J.; Cammi, R.; Pomelli, C.; Ochterski, J. W.; Martin, R. L.; Morokuma, K.; Zakrzewski, V. G.; Voth, G. A.; Salvador, P.; Dannenberg, J. J.; Dapprich, S.; Daniels, A. D.; Farkas, Ö.; Foresman, J. B.; Ortiz, J. V.; Cioslowski, J.; Fox, D. J. Gaussian 09, Revision D.01; Gaussian, Inc., Wallingford CT, 2013.

(47) Møller, C.; Plesset, M. S. Phys. Rev. 1934, 46, 618-622.

(48) Woon, D. E.; Dunning Jr., T. H. J. Chem. Phys. 1993, 98, 1358-1371.

(49) Tao, J. M.; Perdew, J. P.; Staroverov, V. N.; Scuseria, G. E. Phys. Rev. Lett. 2003, 91, 146401.

(50) Grimme, S.; Antony, J.; Ehrlich, S.; Krieg, H. J. Chem. Phys. 2010, 132, 154104.

(51) Dunning Jr., T. H. J. Chem. Phys. 1989, 90, 1007-1023.

(52) Kendall, R. A.; Dunning Jr., T. H.; Harrison, R. J. J. Chem. Phys. 1992, 96, 6796-6806.

(53) Woon, D. E.; Dunning Jr., T. H. J. Chem. Phys. 1993, 98, 1358-1371.

(54) Grimme, S.; Ehrlich, S.; Goerigk, L. J. Comp. Chem. 2011, 32, 1456-1465. 
(55) Pople, J. A.; Head-Gordon, M.; Raghavachari, K. J. Chem. Phys. 1987, 87, 5968-5975.

(56) Mackie, I. D.; DiLabio, G. A. J. Chem. Phys. 2011, 135, 134318.

(57) Becke, A. D. J. Chem. Phys. 1993, 98, 5648-5652.

(58) Stephens, P. J.; Devlin, F. J.; Chabalowski, C. F. J. Phys. Chem. 1994, 98, 11623-11627.

(59) Goerigk, L.; Grimme, S. J. Chem. Theory Comput. 2011, 7, 291-309.

(60) Chai, J. D.; Head-Gordon, M. Phys. Chem. Chem. Phys. 2008, 10, 6615-6620.

(61) Dunning Jr., T. H. J. Chem. Phys. 1989, 90, 1007-1023.

(62) Kendall, R. A.; Dunning Jr., T. H.; Harrison, R. J. J. Chem. Phys. 1992, 96, 6796-6806.

(63) Weigend, F.; Ahlrichs, R. Phys. Chem. Chem. Phys. 2005, 7, 3297-3305.

(64) Boys, S. F.; Bernardi, F. Mol. Phys. 1970, 19, 553-566.

(65) Jeziorski, B.; Moszynski, R.; Szalewicz, K. Chem. Rev. 1994, 94, 1887-1930.

(66) Hohenstein, E. G.; Sherrill, C. D. J. Chem. Phys. 2010, 133, 014101.

(67) a) Hohenstein, E. G.; Jaeger, H. M.; Carrell, E. J.; Tschumper, G. S.; Sherrill, C. D. J. Chem. Theory Comput. 2011,7, 2842-2851 b) Hohenstein, E. G.; Sherrill, C. D. WIREs Comput. Mol. Sci. 2012, 2, 304-326. c) Parker, T. M.; Burns, L. A.; Parrish, R. M.; Ryno, A. G.; Sherrill, C. D. J. Chem. Phys. 2014, 140, 094106.

(68) Stone, A. J.; Misquitta, A. J. Chem. Phys. Lett. 2009, 473, 201-205. 
(69) Turney, J. M.; Simmonett, A. C.; Parrish, R. M.; Hohenstein, E. G.; Evangelista, F.; Fermann, J. T.; Mintz, B. J.; Burns, L. A.; Wilke, J. J.; Abrams, M. L.; Russ, N. J.; Leininger, M. L.; Janssen, C. L.; Seidl, E. T.; Allen, W. D.; Schaefer, H. F.; King, R. A.; Valeev, E. F.; Sherrill, C. D.; Crawford, T. D. WIREs Comput. Mol. Sci. 2012, 2, 556-565.

(70) Bulat, F. A.; Toro-Labbe, A.; Brinck, T.; Murray, J. S.; Politzer, P. J. Mol. Model. 2010, $16,1679-1691$.

(71) Bondi A. J. Phys. Chem. 1964, 68, 441-451.

(72) Morgado, C. A.; McNamara, J. P.; Hillier, I. H.; Burton, N. A.; Vincent, M. A. J. Chem. Theory Comput. 2007, 3, 1656-1664.

(73) a) Hohenstein, E. G.; Sherrill, C. D. J. Phys. Chem. A 2009, 113, 878-886. b) Sherrill, D. C. Acc. Chem. Res. 2013, 46, 1020-1028.

(74) Biegler-König, F. W.; Bader, R. F. W.; Tang, T. H. J. Comput. Chem. 1982, 3, 317-328.

(75) Lu, T.; Chen, F. W. J. Comput. Chem. 2012, 33, 580-592.

(76) AIMAll (Version 15.05.18), Keith, T. A., TK Gristmill Software, Overland Park KS, USA, 2015 (aim.tkgristmill.com)

(77) Contreras-García, J.; Johnson, E. R.; Keinan, S.; Chaudret, R.; Philip, Piquemal J.; Beratan, D. N.; Yang, W. J. Chem. Theory Comput. 2011, 7, 625-632. 


\title{
Table of Contents Graphic
}

\section{Preferred geometries and energies of sulfur-sulfur interactions in crystal structures}

\author{
Ivana S. Antonijević, ${ }^{a}$ Goran. V. Janjić, ${ }^{a}$ Miloš. K. Milčić, ${ }^{b}$ Snežana. D. Zarićc ${ }^{b, c}$ \\ ${ }^{a}$ Institute of Chemistry, technology and metallurgy, University of Belgrade, Njegoševa 12, \\ Belgrade, Serbia \\ ${ }^{\mathrm{b}}$ Department of Chemistry, University of Belgrade, Studentski trg 12-16, Belgrade, Serbia \\ ${ }^{\mathrm{c}}$ Department of Chemistry, Texas A\&M University at Qatar, P. O. Box 23874, Doha, Qatar
}

\begin{abstract}
The $\mathrm{S}$ * S interactions between cysteine residues were studied by analyzing crystal structures from Cambridge Structural Database and by quantum chemical calculations. The parallel orientation of cysteine residues is the preferred orientation in crystal structures, with the strongest energy of $1.80 \mathrm{kcal} / \mathrm{mol}$. The strongest $\mathrm{S}^{\cdots} \mathrm{S}$ interaction has energy of $-2.20 \mathrm{kcal} / \mathrm{mol}$ and orientation with maximized electrostatic interaction.
\end{abstract}

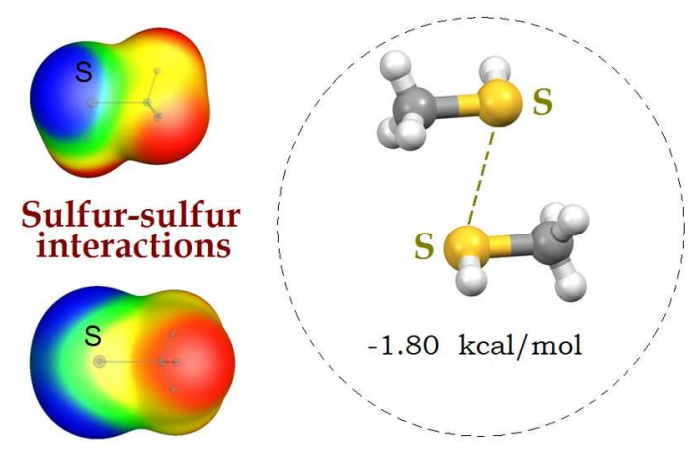

